\title{
Experimental arthritis in C57black/6 normal and beige (Chediak-Higashi) mice: in vivo and in vitro observations on cartilage degradation
}

\author{
JOOST SCHALKWIJK, LEO A B JOOSTEN, WIM B VAN DEN BERG, \\ AND LEVINUS B A VAN DE PUTTE
}

From the Department of Rheumatology, University Hospital St Radboud, University of Nijmegen, Geert Grooteplein Zuid 8, $6500 \mathrm{HB}$ Nijmegen, The Netherlands

SUMMARY Mice with the beige mutation are known to be deficient for polymorphonuclear leucocyte (PMN) elastase and cathepsin $\mathrm{G}$ and can therefore be used as a model for protease dependence of tissue destruction in inflammatory conditions. The in vitro and in vivo effect of $\stackrel{\odot}{\supset}$ PMN activation on cartilage damage in C57black/6 normal and beige mice was measured. In vitro $\vec{z}$ it was found that stimulation of normal PMNs with chemotactic peptide caused degradation of articular cartilage matrix owing to an elastase dependent mechanism; PMNs of beige mice did not induce degradation of cartilage. In vivo, using zymosan induced arthritis, which is a model ${ }_{\mathbb{D}}^{\vec{D}}$ characterised by a PMN-rich infiltrate and exudate, no significant differences were foumd between the two strains with respect to $(a)$ joint oedema formation as measured $0 y$ technetium-99m uptake; $(b)$ matrix degradation as measured quantitatively and with histolog ;; (c) chondrocyte proteoglycan synthesis as measured by radiosulphate uptake. At day 28 afterro induction of arthritis, when inflammation is waning, no differences in end stage irreversible damage to joint tissues were found. The relevance of these observations to the supposed role of PMN derived neutral proteases in joint inflammation is discussed.

Key words: elastase, cathepsin G.

Lysosomal proteases secreted by inflammatory cells such as polymorphonuclear leucocytes (PMNs) and macrophages have been strongly implicated in the pathological degradation of tissues in various disorders, including lung emphysema, ${ }^{12}$ nephritis, ${ }^{3}$ and arthritis. ${ }^{4-6}$ In particular, neutral proteases such as elastase, cathepsin $\mathrm{G}$, and collagenase could be of interest as it has been shown (largely in vitro) that they have the potency to degrade a variety of connective tissue molecules at physiological $\mathrm{pH} .^{4-9}$ On the other hand, the role of these proteases has been questioned as there is a large amount of protease inhibitor present in body fluids such as plasma and synovial fluid. ${ }^{10}$ Recently, however, we have shown that elastase can escape inactivation by $\alpha_{1}$ proteinase inhibitor, thereby causing cartilage

Accepted for publication 24 March 1988.

Correspondence to Dr Joost Schalkwijk, Department of Rheumatology, University Hospital St Radboud, Geert Grooteplein Zuid 8, 6500 HB Nijmegen, The Netherlands. degradation even in the presence of a physiological concentration of $\alpha_{1}$ proteinase inhibitor. ${ }^{6}$ As there is at the moment no conclusive evidence for a role of $\%$ elastase in cartilage degradation in vivo we examined $\overline{3}$. the effect of experimental joint inflammation in C57black/6 normal and beige mice, the latter being deficient for PMN elastase and cathepsin G. ${ }^{11}$ Usingo quantitative methods we showed that in vitro normal PMNs can degrade cartilage, whereas the을 PMNs from beige mice are without effect. In vivo, however, using an experimental arthritis model, there is no difference in the rate of cartilage $N$ degradation between the two mice strains.

\section{Materials and methods}

A N I M A L S

Male, normal C57Bl/6 and beige C57B1/6 (bg/bg) mice were obtained from Harlan OLAC Ltd, UK. ${ }^{\circ}$ Mice were fed a standard diet and tap water freely. They were used between the age of 10 and 16 weeks. 
C H E M I C A L S

Zymosan, cytochrome $c$, superoxide dismutase, $N$ formyl-methionyl-leucyl-phenylalanine (FMLP), Ellman's reagent, cytochalasin B, and phorbol myristate acetate (PMA) were obtained from Sigma Chemicals Co, USA. Methoxysuccinyl-alanyl-alanylprolyl-valyl-chloromethylketone (MAAPV-CMK), methoxysuccinyl-alanyl-alanyl-prolyl-valyl - aminomethylcoumarin, and succinyl-phenylalanyl-leucylthiobenzylester were obtained from Bachem, Bubendorf, Switzerland.

\section{ENZYME MEASUREMENTS}

Elastase was measured fluorimetrically using methoxysuccinyl-alanyl-alanyl-prolyl-valyl-aminomethylcoumarin as substrate. ${ }^{12}$ In this assay 7-amino-4-methylcoumarin is released from the peptide and measured at $370 \mathrm{~nm}$ (excitation wavelength) and $460 \mathrm{~nm}$ wavelength (emission wavelength). Cathepsin $\mathrm{G}$ was measured using succinyl-phenylalanylleucyl-thiobenzylester as substrate. ${ }^{13}$ In this assay cathepsin $G$ acts as an esterase that specifically cleaves off the benzylthiol which could then be detected colorimetrically in a coupled assay with Ellman's reagent. Enzyme measurements were performed on extracts of mouse peritoneal exudates, which were obtained by the injection of $0.5 \mathrm{ml}$ paraffin oil. After 24 hours the cells (90-95\% PMNs) were collected from the peritoneal cavity, washed, and extracted in $0.5 \mathrm{M} \mathrm{NaCl}, 0.1 \mathrm{M}$ trometamol (TRIS), $\mathbf{0} \cdot 4 \%$ cetrimide, $0 \cdot 1 \%$ Triton $\mathrm{X}-100 \mathrm{pH} 8 \cdot 0$.

Values for the enzyme content of mouse PMNs were obtained as the mean (SD) of three separate measurements on pools of peritoneal exudate cells of four mice in each experiment.

\section{SUPEROXIDE MEASUREMENT}

Superoxide production was measured by the cytochrome $c$ reduction method as described previously. ${ }^{14}$ We used peritoneal exudate cells which were obtained as described above. Cells were suspended in Dulbecco's phosphate buffered saline (DPBS) and stimulated with PMA $(100 \mu \mathrm{g} / \mathrm{l})$. The superoxide dismutase inhibitable cytochrome $c$ reduction was converted to nmoles of superoxide produced per $10^{6}$ cells per minute, assuming a molar extinction coefficient of $21000 \mathrm{M}^{-1} \mathrm{~cm}^{-1}$ (difference between reduced and oxidised forms).

Values for superoxide production by beige and normal mice (mean (SD)) were obtained from six animals per strain.

DEGRADATION OF ARTICULAR CARTILAGE IN VIT RO

The capacity of PMNs to degrade articular cartilage in vitro was measured as described previously for human peripheral blood PMNs. ${ }^{6}$ Briefly, PMNs suspended in DPBS $\left(5 \times 10^{6} \mathrm{cells} / \mathrm{ml}\right)$ were added to murine patellar cartilage which was prelabelled with $\left[{ }^{35}\right.$ S $]$ sulphate. The PMNs were stimulated with FMLP $\left(10^{-6} \mathrm{M}\right)$ in the presence of cytochalasin B $(5 \mathrm{mg} / \mathrm{l})$. Incubations were performed at $37^{\circ} \mathrm{C}$ in microtitre plates. After a two hour incubation period the cartilage samples were washed and the residual radioactivity in the cartilage measured by liquid scintillation counting and expressed as a percentage of the initial radioactivity. As shown in previous reports ${ }^{15}$ over $90 \%$ of the ${ }^{35}$ S]sulphate is associated with the glycosaminoglycan fraction. Loss of ${ }^{35} \mathrm{~S}$ labelled material from the cartilage is therefore taken to indicate breakdown of proteoglycans.

ARTHRITIS INDUCTION: MEASUREMENT OF IN F L A M M A TION

Joint inflammation was induced in beige and normal mice in the right knee joint by the intra-articular injection of $180 \mu \mathrm{g}$ of zymosan as previously described. ${ }^{16}$ Arthritis was measured by technetium$99 \mathrm{~m}\left({ }^{99 \mathrm{~m}} \mathrm{Tc}\right)$ uptake as described before. ${ }^{16} 17$ Briefly, the accumulation of ${ }^{99 \mathrm{~m}} \mathrm{Tc}$ is measured in the right (R) and left (L) control knee joint and expressed as a ratio $(R / L)$. This ratio is taken as a measure of joint swelling. Ratios exceeding $1 \cdot 1$ were considered to indicate inflammation of the right knee.

H IS T O L OG Y

Mouse knee joints (six animals per group) were processed for histology as described before. Histology of zymosan induced arthritis was carried out on days 2,7 , and 28 after induction of arthritis. Arthritis was scored on serial sections (haematoxylin and eosin staining) using a combined score of exudate in the joint space and synovial infiltration. ${ }^{18}$ Proteoglycan depletion of cartilage matrix was scored semiquantitatively on Saffranin $O$ stained sections.

MEASUREMENT OF IN VIVO CARTILAGE DEGRA D A T I O N

Cartilage of beige and normal mice was labelled in vivo with $\left[{ }^{35} \mathrm{~S}\right]$ sulphate by the intraperitoneal injection of $1.85 \mathrm{MBq}$ radiosulphate in saline. After 24 hours, when labelling was completed (the bulk of the radiosulphate is cleared from the circulation), arthritis was induced as described above. At 12, 24, and 48 hours after induction of arthritis the patellar cartilage of the right (arthritic) and left (control) knee joint was dissected and the ${ }^{35} \mathrm{~S}$ content measured by liquid scintillation counting (five mice at each time). Radiolabel in the patellar cartilage 
was shown to be associated with the glycosaminoglycan fraction. ${ }^{15}$ Cartilage degradation is expressed as the percentage of radiolabelled proteoglycans lost from the arthritic patella compared with the control.

\section{INHIBITION OF CHONDROCYTE}

\section{PROTEOGLYCAN SYNTHESIS}

At several intervals after the induction of arthritis mice were killed, and the patellae of the right (inflamed) and left (control) joint were dissected. $\left[{ }^{35} \mathrm{~S}\right]$ Sulphate incorporation in vitro was performed as described in earlier reports. ${ }^{1314}$ The incorporation into the right patella was compared with that into the control and taken as a measure for proteoglycan synthesis.

\section{Results}

\section{PMN FUNCTION IN BEIGE AND}

\section{NORMAL MICE}

Both oxygen metabolites and lysosomal proteases are known to affect cartilage integrity in vitro. ${ }^{4-7} 14$ Therefore we measured the superoxide production of PMNs from beige and normal mice and checked the elastase and cathepsin G content, which was reported to be lower in the beige mice. ${ }^{11}$ Mouse peritoneal exudate cells were obtained by the injection of paraffin oil and harvested 24 hours later. The cells were washed and suspended in DPBS. Superoxide production by PMNs after stimulation with PMA was not significantly different for PMNs from beige and normal mice: $3.4(0.5)$ and $2.9(0.7)$ $\mathrm{nmol} \mathrm{O}_{2} / \mathrm{min} / 10^{6}$ cells respectively. We could confirm earlier observations that PMNs from beige mice are lower in cathepsin $G$ and elastase than those from normal mice, though the values were somewhat higher than reported by others. ${ }^{11} \mathrm{We}$ found that the elastase and cathepsin $\mathrm{G}$ content of PMNs from beige mice were $14(3 \%)$ and $11(5 \%)$ respectively, compared with PMNs from normal mice (mean (SD) of three measurements on pools of five peritoneal exudates).

\section{IN VITRO CARTILAGE DEGRADATION BY ACTIVATED PMNS}

Mouse patellar cartilage, prelabelled with $\left[{ }^{35}\right.$ S]sulphate in vitro, was exposed to PMNs from beige and normal mice. Table 1 shows that resting PMNs from either strain did not induce measurable cartilage degradation in a two hour incubation. Upon stimulation with FMLP in the presence of cytochalasin $B$, agents that are known to induce superoxide production and degranulation, normal PMNs caused nearly $70 \%$ degradation of cartilage proteoglycans, whereas no significant cartilage breakdown was seen with PMNs from beige mice.
Table 1 In vitro cartilage degradation by PMNs from beige and normal mice. Values are mean (SD)

\begin{tabular}{|c|c|}
\hline $\begin{array}{l}\text { Treatment of } \\
\text { cartilage }\end{array}$ & $\begin{array}{l}\int^{35} S / S \text { Sulphate content of } \\
\text { patellar cartilage }(\mathrm{cpm})\end{array}$ \\
\hline Dulbecco's & 961 (197) \\
\hline Normal PMNs non-stimulated & $845(246)$ \\
\hline Normal PMNs stimulated & $295(71)^{*}$ \\
\hline Beige PMNs non-stimulated & 857 (127) \\
\hline Beige PMNs stimulated & $909(124) \dagger$ \\
\hline $\begin{array}{l}\text { Normal PMNs stimulated in the } \\
\text { presence of MAAPV-CMK } \$\end{array}$ & $940(104) \ddagger$ \\
\hline
\end{tabular}

Cartilage, prelabelled with $\left[{ }^{35} \mathrm{~S}\right]$ sulphate (six patellae a group) was incubated with $2 \times 10^{7}$ mouse PMNs/ml in Dulbecco's medium. PMNs were stimulated with FMLP $\left(10^{-6} \mathrm{M}\right)$ and cytochalasin B $(10 \mathrm{mg} / \mathrm{l})$. After two hours the ${ }^{35} \mathrm{~S}$ content of the cartilage was.measured and compared with that of cartilage kept in medium or $\overrightarrow{-}$ exposed to non-stimulated cells. The specific elastase inhibitorio MAAPV-CMK was added at $200 \mu \mathrm{mol} / \mathrm{l}$.

${ }^{*} \mathrm{p}<0.005$ compared with non-stimulated normal PMNs, two tailed Mann-Whitney U test.

$\nmid$ Not significantly different from non-stimulated PMNs from beige mice.

$\ddagger \mathrm{p}<0 \cdot 005$, significantly different from stimulated normal PMNs in the absence of MAAPV-CMK.

§MAAPV - CMK = methoxysuccinyl - alanyl - alanyl - prolyl - valyl $-\frac{\vec{\sigma}}{\mathrm{O}}$ chloromethylketone.

The mechanism of cartilage breakdown was show to be elastase dependent as the specific elastașe inhibitor MAAPV-CMK completely prevented cartilage degradation. MAAPV-CMK did not interfere with PMN stimulation. The results for cartilage $\stackrel{\circ}{\circ}$ degradation by PMNs from normal mice coincide $\stackrel{\mathbb{Q}}{2}$ with data we recently published on the same test $\overrightarrow{\overrightarrow{0}}$ system with human PMNs. ${ }^{6}$

EXPERIMENTAL ARTHRITIS IN BEIGE AND NORMAL MICE

Arthritis was induced by the injection of $180 \mu \mathrm{g}$ zymosan into the right knee joint. At days 2 and $7 \frac{0}{3}$ arthritis was measured by ${ }^{99 \mathrm{~m}} \mathrm{Tc}$ uptake, which is a measure for joint oedema. Table 2 shows ${ }^{99 m} \mathrm{Tc} \delta$

Table 2 Measurement of arthritis in beige and normal mice. Values are mean $(S D)$

\begin{tabular}{|c|c|c|}
\hline \multirow[t]{2}{*}{ Mice } & \multicolumn{2}{|l|}{${ }^{99 m} T c$ ratio } \\
\hline & Day 2 & Day 7 \\
\hline Beige & $1.91(0.19)$ & $1.26(0 \cdot 14)$ \\
\hline Normal & $1.90(0 \cdot 16)$ & $1.24(0.08)$ \\
\hline
\end{tabular}

Six mice per group were injected with $180 \mu \mathrm{g}$ of zymosan at day $0 . £$ At days 2 and 7 arthritis was measured by the ${ }^{99 \mathrm{~m}}$ Tc uptake method. The ratio of ${ }^{99 m} \mathrm{Tc}$ uptake in the right and left knee joint is taken as a measure for joint oedema.

No significant differences were measured, two tailed Mann- $\mathbb{D}$ Whitney U test. 
uptake for both mouse strains. No significant differences were noted at any time.

At days 2, 7, and 28 animals were killed for histology. Inflammation was scored on serial sections using cellular exudate in the joint space, synovial infiltration, and depletion of cartilage matrix as seen on Saffranin O stained sections. No differences in histological parameters were seen. Beige mice showed a strong inflammatory response against zymosan (Figs 1, 2, and 3). The acute phase of arthritis was characterised by a PMN-rich exudate in the joint space and a heavily infiltrated synovium. At day 28 chondrocyte death and bone apposition could be seen in some of the animals. The histological picture of zymosan induced arthritis in beige mice was similar to that of normal C57black mice as described in earlier reports. ${ }^{16} 1819$

\section{QUANTITATIVE MEASUREMENT OF}

\section{CARTILAGE DAMAGE}

To investigate possible differences in cartilage degradation and inhibition of chondrocyte metabolism between beige and normal mice we used ${ }^{35}$ S]sulphate labelling of cartilage proteoglycans. Cartilage was labelled in vivo by $\left.{ }^{35} \mathrm{~S}\right]$ sulphate, and after 24 hours, when labelling was complete, arthri-

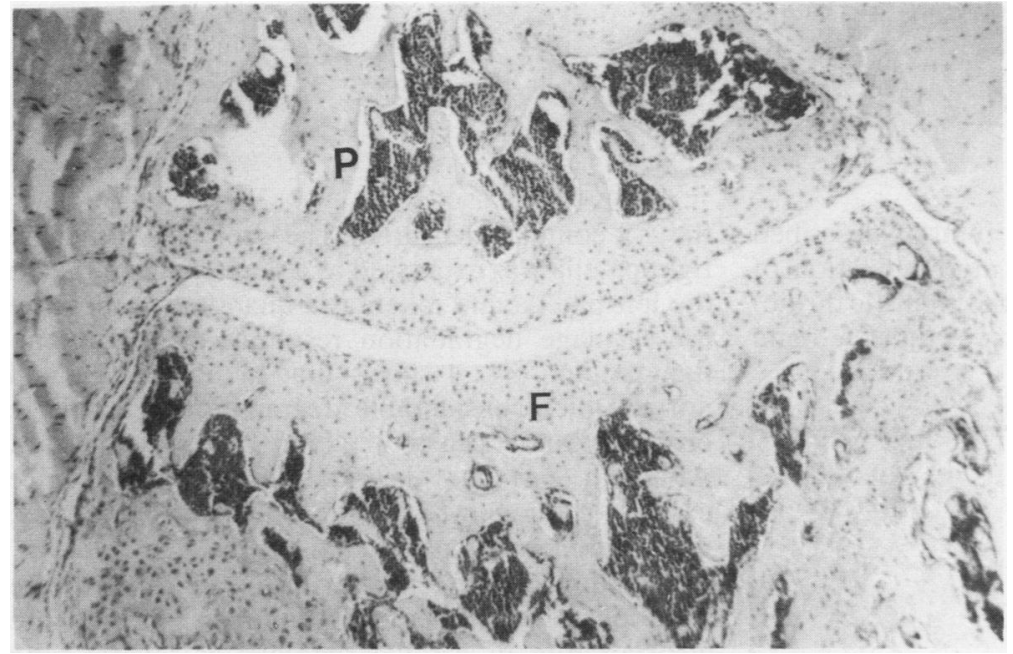

Fig. 1 Normal knee joint of C57Bl/6 beige mouse. Section of normal joint from a $\mathrm{C} 57 \mathrm{Bl} / 6$ beige mouse. Haematoxylin and eosin ( $H \& E$ ) staining. $P=$ patella; $F=$ femur.

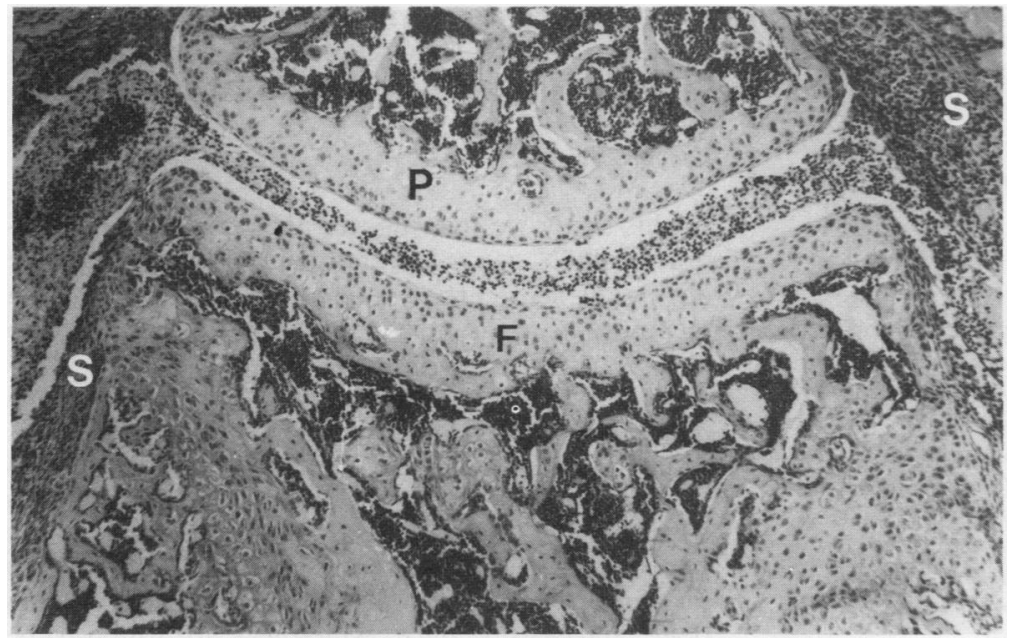

Fig. 2 Arthritic knee joint of C57Bl/6 beige mouse. Section of inflamed knee joint two days after induction of arthritis with $180 \mu \mathrm{g}$ zymosan. Note the exudate in the joint space and the cellular infiltration in the synovium. $H \& E$ staining. $P=$ patella; $F=$ femur; $S=$ synovium. 


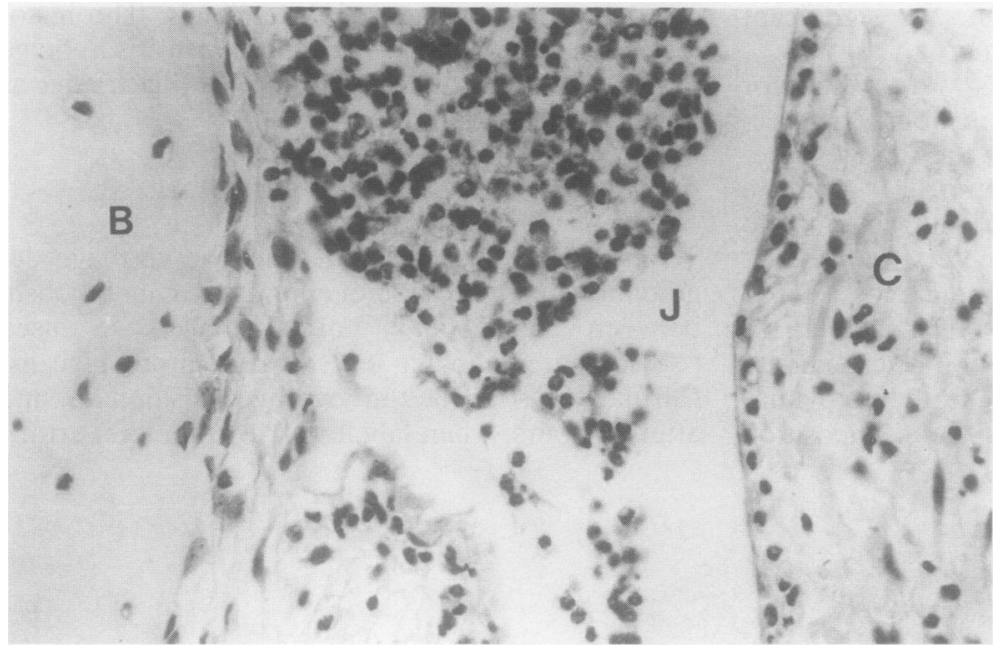

Fig. 3 Exudate cells in joint space of C57Bl/6 beige mouse. Section of ${ }^{\text {on }}$ an arthritic knee joint (day 2

zymosan induced arthritis). Note that the PMN is the predominant cell type in the exudate. $H \& E$ staining. $J=$ joint space; $C=$ joint capsule; $B=$ bone.

tis was induced in the right knee joint as described above. At 12, 24, and 48 hours after induction of arthritis the patellar cartilage of the right (arthritic) and the left (control) knee joints was dissected and

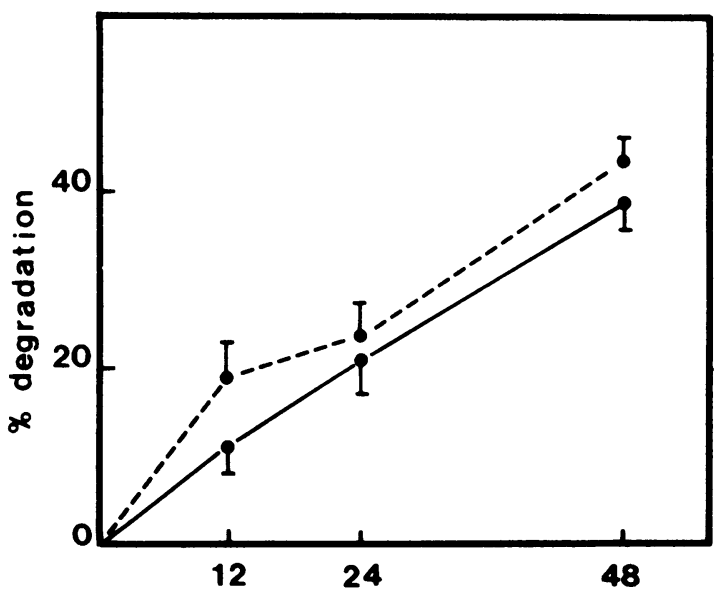

hours

Fig. 4 Degradation of articular cartilage in vivo. Cartilage was prelabelled in vivo with ${ }^{35}$ SJsulphate. At 12, 24, and 48 hours after induction of arthritis in the right knee joint the patellar cartilage of both knee joints was dissected and the amount of radioactivity determined. Degradation of patellar cartilage in the arthritic joint was calculated relative to the left (control) joint. The cartilage of both normal (- - - ) and beige (-) mice showed considerable breakdown within 48 hours. No significant differences were noted between the two strains. Each point represents the mean (SEM) of five mice. the ${ }^{35} \mathrm{~S}$ content measured. The radioactivity in the $\frac{\$}{3}$ right patella was expressed as a percentage of that in ${ }_{\Phi}$ the left patella and taken as a quantitative measuze for cartilage degradation resulting from joint i $-\infty$ flammation. Fig. 4 shows that in both beige and normal mice considerable degradation of cartilage proteoglycans occurred (about $40 \%$ at day 2 ). Although cartilage degradation in normal mice $\frac{}{0}$ tended to be somewhat higher than in the beige mice, $\stackrel{2}{\varrho}$ the difference was never statistically significant.

To study the effect of arthritis on chondrocyte $\overrightarrow{\vec{P}}$ metabolism we measured the in vitro $\left[{ }^{35} \mathrm{~S}\right]$ sulphate $\frac{\circ}{3}$ incorporation in patellar cartilage at several time $=$ intervals after induction of arthritis. Both normalo and beige mice showed about $50 \%$ inhibition of proteoglycan synthesis in cartilage from the arthritic knee joint compared with that from the left control joint. Again, no significant difference was noted $\stackrel{3}{\text {. }}$. between beige and normal mice (data not shown).

\section{Discussion}

In this study we investigated the possible contribution of PMN neutral proteases to cartilage damage during the acute phase of experimental arthritis. We $\sigma$ therefore used the beige mutation of the C57black/6 N mouse, which is reported to be deficient for PMN $N$ elastase and cathepsin $G(3-7 \%$ of the normalo mice). We confirmed the deficiency of beige mice 0 though the elastase and cathepsin $G$ content was ${ }_{\mathbb{D}}$ slightly higher (11 and $14 \%$ respectively) than? reported by others. ${ }^{11}$ As oxygen metabolites are known to affect chondrocyte metabolism ${ }^{14}$ we also measured superoxide production by PMNs from beige and normal mice, which was not found to be 
significantly different. In vitro experiments using mouse patellar cartilage as a target showed that stimulated PMNs from normal mice readily degraded cartilage proteoglycans by an elastase dependent mechanism, whereas the PMNs from beige mice did not. To ascertain the relevance of these findings in vivo we measured cartilage damage in a model of experimental arthritis. To this end we chose zymosan induced arthritis, a model which is characterised by an abundant PMN infiltrate and exudate in the acute phase of inflammation. ${ }^{18}$ The acute inflammatory response induces inhibition of chondrocyte proteoglycan synthesis and degradation of cartilage matrix. ${ }^{18} 19$ If it is assumed that neutral proteases contribute to these phenomena one would expect a difference in cartilage damage between the two strains. We did not, however, find significant differences, either with quantitative measurements $\left({ }^{35} \mathrm{~S}\right.$ labelling) or at the histological level.

Neutral proteases have been strongly implicated in the pathogenesis of a number of disorders, including lung emphysema, ${ }^{12}$ nephritis, ${ }^{3}$ and arthritis. ${ }^{4-6}$ In vitro it was shown that enzymes such as elastase ${ }^{4}$ and cathepsin $G^{7}$ purified from human PMNs could degrade articular cartilage. On the other hand, it was argued that the large amount of protease inhibitors in body fluids would prevent these proteases from degrading the extracellular matrix. ${ }^{10}$ It was shown that elastase can escape inactivation by $\alpha_{1}$ proteinase inhibitor by oxidative inactivation of the inhibitor. ${ }^{1}$ Recently we showed that activated PMNs in vitro can degrade articular cartilage even in the presence of physiological levels of $\alpha_{1}$ proteinase inhibitor owing to exclusion of the inhibitor from the matrix. ${ }^{6}$ Therefore elastase was considered likely to cause cartilage damage in vivo during active arthritis. This would then justify the search for elastase inhibitors that could be applied in rheumatic diseases. Recently, a number of synthetic low molecular weight elastase inhibitors have been reported, which may be useful in such diseases as lung emphysema, adult respiratory distress syndrome, and rheumatoid arthritis. ${ }^{20}$

The results given in this report can be interpreted in several ways. Firstly, one could assume that during acute arthritis there is a substantial 'overkill' by other mediators (oxygen metabolites, enzymes, prostanoids, cytokines). Therefore, the absence of two enzymes (elastase and cathepsin $\mathrm{G}$ ) would not make much difference. We have shown that oxygen metabolites, though they suppress chondrocyte metabolism in vitro, do not cause cartilage breakdown in experimental models of arthritis. ${ }^{14}$ On the other hand, cytokines such as interleukin 1 and tumour necrosis factor are likely candidates for the observed cartilage damage in this arthritis model. ${ }^{21}$
Both degradation of cartilage matrix and inhibition of proteoglycan synthesis can be explained by the action of cytokines. The contribution of interleukin 1 in experimental arthritis would be difficult to verify as there are no specific inhibitors of interleukin 1 available at the moment. Apart from elastase and cathepsin G, cartilage damage could also be induced by other PMN derived proteases, such as cathepsin D, plasminogen activator, and collagenase. These three enzymes were reported to be normal in the beige mice. ${ }^{11}$ In addition, proteases derived from synovial cells, such as collagenase, ${ }^{22}$ rather than from PMNs could also be involved.

A second explanation could be that in beige mice the residual neutral protease activity (11-14\%) would still be enough to induce cartilage breakdown. We performed dose-response experiments with varying degrees of inflammation and did not notice significant differences in cartilage breakdown, which one would expect if there were a critical concentration of elastase in the joint with respect to cartilage degradation. A third possibility would be a higher turnover of PMNs from beige mice in the inflamed joint. Discharge of elastase and cathepsin $G$ from senescent PMNs could thus increase the protease 'load' in the joint. There are no published data indicating that this is the case, nor do we have data on this point. Finally, it is possible that the role of certain mediators in tissue damage depends on the model of inflammation or arthritis. The apparent lack of neutral protease involvement in zymosan induced arthritis could be caused by the action of other mediators that are pertinent to this type of inflammation. We are, therefore, currently undertaking studies on the role of neutral proteases in several other models of arthritis and inflammation. Once the data of these studies are available a more definitive statement on the role of elastase and cathepsin $G$ in tissue damage can be given.

There are a few other reports on the possible role of neutral proteases in animal models of inflammation using beige mice. It has been shown that in lung injury following systemic complement activation neutral proteases were of limited importance, as beige mice showed no differences from controls. ${ }^{23}$ Recently, it was suggested that collagen type II arthritis could not be transferred passively (with antibodies) to C57black/6 beige mice as opposed to C57black/6 normal mice. ${ }^{24}$ These experiments, however, do not provide us with a clue for the role of neutral proteases in cartilage destruction as injection of anticollagen type II antibodies into beige mice failed to elicit PMN infiltration and exudation in the joint.

In conclusion we suggest that in vitro experiments using purified cells or mediators should be inter- 
preted with caution. In this report we describe an apparent discrepancy between in vivo and in vitro results. On the basis of in vitro results ${ }^{4-6}$ one would predict that elastase is an important mediator for cartilage damage. The in vivo experiments, however, contradict (or at least weaken) this conclusion.

This study was supported by the Dutch League against Rheumatism and the Netherlands Organisation for the Advancement of Pure Research (ZWO-Medigon). Liduine van den Bersselaar and the staff of the Central Animal Laboratory are acknowledged for technical assistance.

\section{References}

1 Carp H, Janoff A. In vitro suppression of serum elastaseinhibitory capacity by reactive oxygen species generated by phagocytosing polymorphonuclear leukocytes. J Clin Invest 1979; 63: 793-7.

2 Johnson D, Travis J. The oxidative inactivation of human $\alpha$-1-proteinase inhibitor. Further evidence for methionine at the reactive center. J Biol Chem 1979; 254: 4022-6.

3 Jenette J C, Tidwell R R, Geratz J D, Bing B H, Falk R J Amelioration of immune complex-mediated glomerulonephritis by synthetic protease inhibitors. Am J Pathol 1987; 127: 499-506.

4 Janoff A, Feinstein G, Malemud C J, Elias J M. Degradation of cartilage proteoglycan by human leukocyte granule neutral proteases - a model of joint injury. I. Penetration of enzyme into rabbit articular cartilage and release of ${ }^{35} \mathrm{SO}_{4}$-labelled material from the tissue. J Clin Invest 1976; 57: 615-24.

5 Bartholomew J, Lowther D A, Handley C J. Changes in proteoglycan biosynthesis following leukocyte elastase treatment of bovine articular cartilage in culture. Arthritis Rheum 1984; 27: 905-11.

6 Schalkwijk J, van den Berg W B, van de Putte L B A, Joosten L A B. Elastase secreted by activated polymorphonuclear leukocytes causes chondrocyte damage and matrix degradation in intact articular cartilage: escape from inactivation by alpha-1. proteinase inhibitor. Br J Exp Pathol 1987; 68: 81-8.

7 Keiser H, Greenwald R, Feinstein G, Janoff A. Degradation of cartilage proteoglycan by human leukocyte granule neutral proteases-a model of joint injury. II. Degradation of isolated bovine nasal cartilage proteoglycan. J Clin Invest 1976; 57: 625-32.

8 Weiss S J, Regiani S. Neutrophils degrade subendothelial matrices in the presence of alpha-1-proteinase inhibitor. Cooperative use of lysosomal proteinases and oxygen metabolites. J Clin Invest 1984; 73: 1297-303.

9 Campbell E J, Senior R M, McDonald J A, Cox D L. Proteolysis by neutrophils. Relative importance of cell-substrate contact and oxidative inactivation of proteinase inhibitors in vitro. J Clin Invest 1982; 70: 845-52.
10 Hadler N M, Spitznagel J K, Quinet R J. Lysosomal enzymes in inflammatory synovial effusions. $J$ Immunol 1979; 123: $572-7$. $\Rightarrow$ 11 Takeuchi K. Wood H. Swank R T. Lysosomal elastase and $\overline{\bar{\sigma}}$ cathepsin $G$ in beige mice. Neutrophils of beige (ChediakHigashi) mice selectively lack lysosomal elastase and cathepsin G. J Exp Med 1986; 163: 665-77.

12 Lammers A M, van de Kerkhof P C M, Schalkwijk J, Mier P D. Elastase, a marker for neutrophils in skin infiltrates. $\mathrm{Br} J \mathbb{\Phi}$ Dermatol 1986; 115: 181-6.

13 Harper J W, Ramirez G, Powers J C. Reaction of peptide thiobenzyl esters with mammalian chymotrypsin-like enzymes: $\vec{O}$ a sensitive assay method. Anal Biochem 1981; 118: 382-7.

14 Schalkwijk J, van den Berg W B, van de Putte L B A, Joosten $\overrightarrow{ }$ L A B. Hydrogen peroxide suppresses the proteoglycan synthesis of intact articular cartilage. J Rheumatol 1985; 12: 10 205-10.

15 De Vries B J, van den Berg W B, van de Putte L B A. Salicylate induced depletion of endogenous inorganic sulfate: its potential. role in the suppression of sulfated glycosaminoglycan synthesis $\overrightarrow{-}$ in murine articular cartilage. Arthritis Rheum 1985; 28: 922-9. $\overrightarrow{0}$

16 Schalkwijk J, van den Berg W B, van de Putte L B A, Joosten $P$ L A B. Cationization of catalase, peroxidase and superoxide dismutase. Effect of improved intraarticular retention on experimental arthritis in mice. J Clin lnvest 1985; 76: 198-205. -

17 van den Berg W B, van de Putte L B A, Zwarts W A, Joosten Z L A B. Electrical charge of the antigen determines intraarticularo antigen handling and chronicity of arthritis in mice. J Clin Invest $\Phi$ 1984; 74: 1850-9

18 Schalkwijk J, van den Berg W B, van de Putte L B A, Joosten $L$ A B, van der Sluis $M$. Effects of experimental joint inflammation on bone marrow and periarticular bone. A study $\vec{c}$ of two types of arthritis, using variable degrees of inflammatioin. Br J Exp Pathol 1985; 66: 435-44.

19 van den Berg W B, Kruijsen M W M, van de Putte L B A, va Beusekom H J, van der Sluis-van der Pol M, Zwarts W $\vec{A}$. Antigen-induced and zymosan-induced arthritis in mice: studies on in vivo cartilage proteoglycan synthesis and chondrocytc death. Br J Exp Pathol 1981; 62: 308-16.

20 Doherty J B, Ashe B M, Argenbright L W, et al. Cephalosporin antibiotics can be modified to inhibit human leukocyte elastase. Nature 1986; 322: 192-4.

21 Saklatvala J. Tumour necrosis factor alpha stimulates resorption and inhibits synthesis of proteoglycan in cartilage. Nature 1986; 322: 547-9.

22 Woolley D E, Brinckerhoff C E, Mainardi C L, Vater C A, Evanson J M, Harris E D. Collagenase production by rheumatoid synovial cells: morphological and immunohistochemical studies of the dendritic cell: Ann Rheum Dis 1979; 38: 262-70.

23 Tvedten $\mathrm{H} \mathrm{W}$, Till G O, Ward P A. Mediators of lung injury in? mice following systemic activation of complement. Am J PatholO 1985; 119: 92-100.

24 Watson W C. Brown P S, Pitcock J A, Townes A S. Passive transfer studies with collagen type II antibody in B10.D2/old and new line and C57bl/6 normal and beige (Chediak-Higashi) $D$ strains: evidence of important roles for $\mathrm{C} 5$ and multiple inflammatory cell types in the development of erosive arthritis. Arthritis Rheum 1987; 30: 460-5. 